\title{
The Synthesis of Highly Active Iridium(I) Complexes and their Application in Catalytic Hydrogen Isotope Exchange
}

\author{
Jack A. Brown, ${ }^{a}$ Alison R. Cochrane, ${ }^{a}$ Stephanie Irvine, ${ }^{a}$ William J. Kerr, ${ }^{a} *$ Bhaskar \\ Mondal, ${ }^{\mathrm{a}}$ John A. Parkinson, ${ }^{\mathrm{a}}$ Laura C. Paterson, ${ }^{\mathrm{a}}$ Marc Reid, ${ }^{\mathrm{a}}$ Tell Tuttle, ${ }^{\mathrm{a}}$ Shalini \\ Andersson, ${ }^{b}$ and Göran N. Nilsson ${ }^{b}$
}

a Department of Pure and Applied Chemistry, WestCHEM, University of Strathclyde, 295 Cathedral Street, Glasgow G1 1XL, United Kingdom

Fax: (+44)-141-548-4822; tel: (+44)-141-548-2959; e-mail: w.kerr@strath.ac.uk

b Medicinal Chemistry, AstraZeneca, R\&D Mölndal, SE-431 83 Mölndal, Sweden

Received: ((will be filled in by the editorial staff))

Supporting information for this article is available on the WWW under http://dx.doi.org/10.1002/adsc.201\#\#\#\#\#.((Please delete if not appropriate)

\begin{abstract}
A series of robust iridium(I) complexes bearing a sterically encumbered $N$-heterocyclic carbene ligand, alongside a phosphine ligand, has been synthesised and investigated in hydrogen isotope exchange processes. These complexes have allowed isotope incorporation over a range of substrates with the use of practically convenient deuterium and tritium gas. Moreover, these active catalysts are capable of isotope incorporation to particularly high levels, whilst employing low catalyst loadings and in short reaction times. In addition to this, these new catalyst species have shown flexible levels of chemoselectivity, which can be altered by simple manipulation of preparative approaches.
\end{abstract}

Furthermore, a number of industrially-relevant drug molecules have also been labelled, including the sulfonamide containing drug, Celecoxib. Alongside detailed NMR experiments, initial mechanistic investigations have also been performed, providing insight into both substrate binding energies, and, more importantly, relative energies of key steps in the mechanistic cycle as part of the overall exchange process.

Keywords: hydrogen isotope exchange; iridium; catalysis deuterium; tritium

\section{Introduction}

Despite colossal financial commitment to drug discovery, the pharmaceutical industry is burdened by unsustainable attrition rates associated with new chemical entities. Accordingly, positioning metabolism and pharmacokinetic studies earlier in such discovery programmes is crucial in assessing the overall properties of a drug candidate and as aligned to reducing the present levels of attrition of over $90 \%{ }^{[1]}$ One key methodology applied extensively within this area is isotopic labelling, which allows the biological fate of a potential drug molecule to be carefully monitored. ${ }^{[2]}$ In particular, transition metalcatalysed hydrogen isotope exchange (HIE) offers a simple and direct technique, which potentially allows the regioselective labelling of fully functionalised molecules (Scheme 1), eliminating the need for any additional synthetic processes or prolonged preparative pathways associated with the installation of an isotopic label.

Whilst various transition metal species have demonstrated activity within the field of $\mathrm{HIE},{ }^{[3-6]}$ for a number of years Crabtree's catalyst, $\left[\operatorname{Ir}(\mathrm{COD})\left(\mathrm{PCy}_{3}\right)(\mathrm{py})\right] \mathrm{PF}_{6}{ }^{[7]}$ was regarded as the industry standard to facilitate such a process. This iridium-based complex demonstrates appreciable

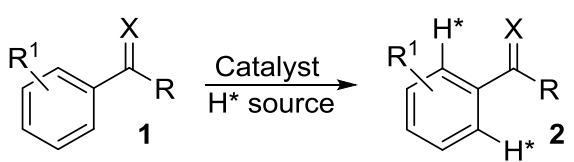

Scheme 1. Ideal hydrogen isotope exchange process.

activity in the labelling of a range of substrates, however, it is often found that (super-)stoichiometric quantities of the catalyst and lengthy reaction times are required to deliver the observed levels of isotope incorporation. ${ }^{[8]}$ In addition, tritiation reactions promoted by Crabtree's catalyst frequently produce considerable quantities of radioactive waste, which is a clear drawback with regards to both cost and environmental concerns. ${ }^{[2 c, 99}$ In view of the issues associated with Crabtree's catalyst, it is evident that alternative metal-based complexes for use in hydrogen isotope exchange would be beneficial to pharmaceutical partners with, in particular, the desired catalysts being capable of labelling an assortment of substrates to high levels of incorporation under mild reaction conditions and with lowered catalyst loadings. Following the work of Nolan $^{[10]}$ and Buriak $\left.{ }^{[11}\right]$ in the field of olefin hydrogenation, we felt that in order to enhance 
catalytic activity in HIE processes, relative to Crabtree's catalyst, greater steric demand around the metal centre, coupled with balanced electronic parameters, was required. ${ }^{[12]}$ In this regard, we have reported on the preparation and application of a series of new iridium complexes bearing a bulky $N$ heterocyclic carbene (NHC), 1,3-bis(2,4,6trimethylphenyl)imidazol-2-ylidene (IMes), alongside an appreciably encumbered phosphine, and which have appreciable potential as highly active catalysts for HIE with deuterium. ${ }^{[13]}$ Additionally, we have shown that these robust and practically accessible iridium species can be applied within the selective reduction of alkenes (and alkynes) ${ }^{[14]}$ and in the $Z$ selective dimerization of terminal alkynes. ${ }^{[15]}$

Herein, we report the activity and selectivity spectrum of this class of iridium complex in the area of deuterium and, importantly, tritium labelling, as well as our initial investigations into the overall mechanism of the hydrogen isotope exchange process with these emerging catalyst species.

\section{Results and Discussion}

First of all, and importantly in a practical sense, a robust and readily utilisable route to our novel $\operatorname{Ir}(\mathrm{I})$ complexes bearing a sterically encumbered NHC in conjunction with a bulky tertiary phosphine ligand was achieved according to a variation of a procedure delineated by Herrmann. ${ }^{[16]}$ The use of sodium ethoxide in the relatively weakly coordinating solvent, benzene, was crucial to allow the in situ generation and introduction of the NHC ligand, avoiding the necessity to pre-form and isolate the free carbene species under glovebox conditions. Following this modified synthetic route, five novel $\operatorname{Ir}(\mathrm{I})$ complexes were delivered in good yields (Table 1). These bright red catalysts are air- and moisture-stable crystalline solids, and have been characterised by NMR and mass spectral techniques. In addition, the structures of complex 5a-c have been confirmed by X-ray crystallography. ${ }^{[13 a]}$

Table 1. Preparation of iridium complexes. ${ }^{\text {a) }}$

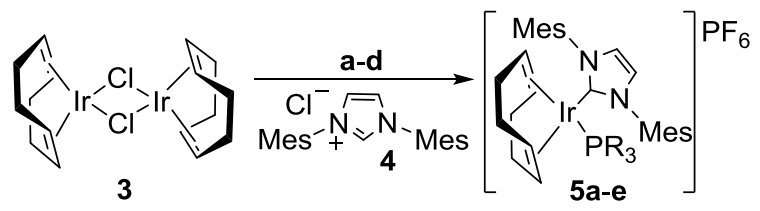

\begin{tabular}{llll}
\hline Entry & $\mathrm{PR}_{3}$ & Complex & Yield $^{\text {b) }}$ \\
\hline 1 & $\mathrm{PP}_{3}$ & $\mathbf{5 a}$ & 62 \\
2 & $\mathrm{PBn}_{3}$ & $\mathbf{5 b}$ & 59 \\
3 & $\mathrm{PMe}_{2} \mathrm{Ph}$ & $\mathbf{5 c}$ & 71 \\
4 & $\mathrm{PMePh}_{2}$ & $\mathbf{5 d}$ & 69 \\
5 & $\mathrm{P}\left(\mathrm{O}^{\mathrm{i} P r}\right)_{3}$ & $\mathbf{5 e}$ & 75 \\
\hline
\end{tabular}

a) Reaction conditions: (a) NaOEt, $\mathrm{PhH}$, r.t., 10 min. (b) 4, $\mathrm{PhH}$, r.t., 5 h. (c) $\mathrm{AgPF}_{6}$, THF, r.t., 30 min. (d) $\mathrm{PR}_{3}$, THF, r.t., 2 h. ${ }^{\text {b) }}$ Isolated yields.
Under the standard reaction conditions developed within our laboratory, employing a catalyst loading of $5 \mathrm{~mol} \%$ in DCM under 1 atmosphere of $\mathrm{D}_{2}$ gas for 16 $\mathrm{h}$, complexes 5a-e facilitated high levels of H/D exchange across a wide range of substrates $(6 \mathbf{6}-\mathbf{i})$ including ketones, amides, and heterocyclic functionalities (Table 2). In general, compounds 7a-g, which are labelled via a 5-membered metallocyclic intermediate (5-mmi), were delivered with high deuterium incorporations in a regioselective and reproducible manner. Furthermore, the isotopic labelling of weakly coordinating nitrobenzene, $\mathbf{6 g}$, proceeded without incident and with no reduction of the nitro moiety, as has been detected with previously employed catalysts. ${ }^{[5 f, 8 b]}$ It is important to highlight that the levels of isotope exchange in benzamide, $\mathbf{6 c}$, were somewhat more variable, ranging from $32 \%$ in the presence of complex $\mathbf{5 a}$, to $90 \%$ in reactions catalysed by complex 5d. Indeed, this substrate is notoriously difficult to label effectively, with 110 mol $\%$ of Crabtree's catalyst being previously

Table 2. HIE studies with complexes 5a-e. ${ }^{\text {a),b) }}$

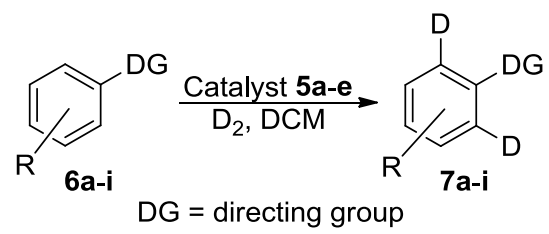<smiles>[2H]c1cccc([2H])c1C(C)=O</smiles>

5a: $97 \%: 5 \mathbf{b}: 98 \%$ 5c: $98 \%$; 5 d: $97 \%$; 5e: $96 \%$<smiles>[2H]c1cc(C)cc([2H])c1C(=O)NCC</smiles>

5a: $98 \%$; 5b: 97\%; 5e: $78 \%$<smiles>[2H]c1cccc([2H])c1[N+](=O)[O-]</smiles><smiles>[2H]c1cccc([2H])c1NC(C)=O</smiles>

5a: 98\%; 5b: 97\%; 5a: 94\%; 5b: 95\%; 5c: $98 \%$; 5 d: $97 \%$; 5 c: $91 \%$; 5 d: $95 \%$ 5e: $97 \%$

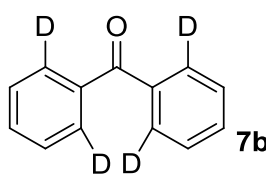

a: $95 \%$; 5 b: $96 \%$; 5e: $94 \%$

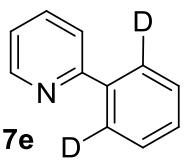

5a: $98 \% ; \mathbf{5 b}: 95 \%$;
5c: $95 \% ; \mathbf{5 d :} 92 \%$; 5e: $96 \%$

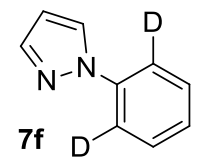

5a: $96 \%$; 5 b: $94 \%$; 5c: $93 \%$; $5 d$ : $94 \%$; 5e: $97 \%$ a) $5 \mathrm{~mol} \%$ of Ir catalyst employed over $16 \mathrm{~h}$. ${ }^{\text {b) }}$ Average incorporation into the positions shown over two separate reaction runs; the percentage given refers to the level of $D$ incorporation over the total number of positions shown, e.g. $97 \%$ for the two possible positions in $7 \mathbf{a}$ indicates $1.94 \mathrm{D}$ incorporation. 
required to deliver the isotopically-enriched product with only a moderate $65 \% \mathrm{D}$ incorporation. ${ }^{8 b]}$ The examination of additional substrates revealed the ability of our novel $\operatorname{Ir}(\mathrm{I})$ complexes to also facilitate isotope exchange in $\mathrm{C}-\mathrm{H}$ bonds positioned five bonds away from the required coordinating functionality i.e. via a 6-membered metallocyclic intermediate (6mmi). This process is believed to be energetically more demanding and, as such, often leads to lower levels of deuteration. In our hands, the simplest substrate of this class, acetanilide, $\mathbf{6 h}$, was labelled up to an excellent 95\% D loading. Furthermore, deuterium incorporation in benzanilide, $\mathbf{6 i}$, occurred with high degrees of exchange observed in positions labelled via both a 5-mmi and a 6-mmi.

To further explore the capabilities of our complexes, a series of rate and activity studies were performed. A loading study revealed that excellent deuterium incorporation is maintained in the presence of catalyst quantities as low as $0.5 \mathrm{~mol} \%$ (Scheme 2). Furthermore, whereas catalyst 5a mediated the $97 \%$ deuteration of $\mathbf{6 a}$ within 120 minutes, more electronrich catalysts, 5b and $\mathbf{5 c}$, delivered more rapid labelling (60 and 90 minutes, respectively). Presumably, the more electron-rich catalysts better facilitate the $\mathrm{C}-\mathrm{H}$ activation process central to the $\mathrm{H} / \mathrm{D}$ exchange reaction. ${ }^{[17]}$

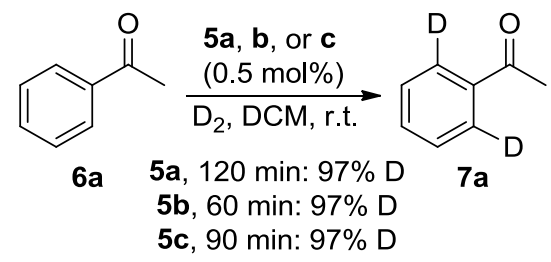

Scheme 2. Catalyst loading and labelling time study.

The excellent levels of efficiency displayed by these complexes prompted us to examine their catalytic activity further. As demonstrated in the labelling of $6 \mathbf{i}$ (Table 2), benzanilide substrates offer two potential sites of labelling, through either a 5- or 6-mmi. It was therefore proposed that the emerging catalysts had the potential to exert regioselective deuteration in substrates of this type. Such discrimination of $\mathrm{H} / \mathrm{D}$ exchange in one position over another would be of particular benefit to pharmaceutical partners, allowing specific drug metabolites to be traced preferentially during in vivo distribution studies. In an attempt to establish such selective HIE, the labelling of benzanilide $\mathbf{6 j}$ was studied. As illustrated in Scheme 3, the use of 5 mol\% of complex $\mathbf{5 c}$ delivered appreciably high levels of isotope incorporation in both positions $a$ and $b$. In contrast, reducing the amount of catalyst present in the reaction system to $0.5 \mathrm{~mol} \%$ resulted in a significant decline in the degree of labelling observed in position $b$, via a 6-mmi, while the elevated level of exchange in position $a$, proceeding via the more favourable 5-mmi, was maintained. A similar result was obtained with the benzanilide derivative $\mathbf{6 k}$, which is capable of labelling through both a 5- and a $6-\mathrm{mmi}$ at three possible sites in the molecule. At a 5 mol\% catalyst loading, complex $\mathbf{5 c}$ showed excellent levels of incorporation into positions $a$ and $b$ (both via a 5-mmi), while position $c$ (via a 6-mmi) showed more moderate $\mathrm{D}$ uptake. Pleasingly, when the catalyst loading was reduced to $0.5 \mathrm{~mol} \%$, not only did we again observe exclusive labelling via the 5$\mathrm{mmi}$ over the $6-\mathrm{mmi}$, there was also selectivity noted between positions $a$ and $b$. The preferential labelling at position $a$ suggests more effective iridium metal centre coordination with the more available oxygen lone pairs within the amide carbonyl group over the oxygen atoms of the nitro unit.
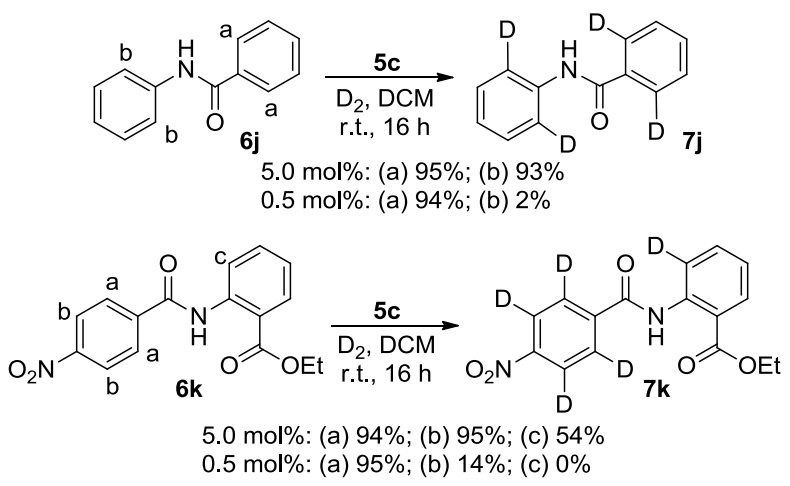

Scheme 3. Labelling selectivity for a 5-mmi over a 6-mmi.

Based on these findings, it was envisaged that our overall protocols could be manipulated to achieve selective labeling into a position labelled via a 6-mmi (Scheme 4). This was accomplished by employing the heavily labelled compound $7 \mathbf{j}(a: 96 \% ; b ; 93 \%)$ as substrate with $\mathrm{H}_{2}$ to allow $\mathrm{H}$ exchange at position $a$, leaving the deuterium in place at position $b$. As shown in Scheme 4, employing $5 \mathrm{~mol} \%$ of complex 5c under an atmosphere of hydrogen resulted in the selective removal of deuterium via the 5-mmi, while the level of $\mathrm{D}$ at position $b$ remained high. Accordingly, this section of our study has shown that it is now possible to access both classes of selectively labelled compounds, which illustrates a further distinct practical advantage delivered by these novel iridium catalyst systems. To our knowledge, this level of labelling selectivity by this direct approach is unprecedented in the literature.

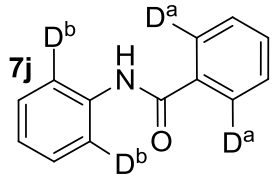

(a) $96 \%$; (b) $93 \%$ (a) $13 \%$; (b) $90 \%$

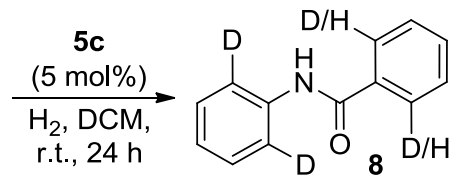

Scheme 4. Selective removal of the D Label via the 5-mmi.

To further illustrate the capabilities of these catalysts, a number of available drug molecules were applied in hydrogen isotope exchange reactions. The 
ability to label fully functionalised drug scaffolds is central to the application of HIE catalysis, especially as aligned to the endeavours of pharmaceutical partners. Pleasingly, complexes 5a-c performed very well with a series of drug substrates at relatively low catalyst loadings and over short reaction times (7l-o; Table 3). Of particular note is the high level of D incorporation in the Pfizer COX-2 inhibitor, Celecoxib, $\mathbf{7 m}$. In addition to the high level of D uptake obtained in position $b$, the $\mathrm{D}$ incorporation at position $a$ represents the first example of deuterium labelling adjacent to a primary sulfonamide moiety as facilitated by complexes of this type ${ }^{[18]}$ albeit at relatively moderate levels. Furthermore, SanofiAventis' anti-androgen Nilutamide, $\mathbf{7 n}$, provides a further example of preferential labelling via a $5-\mathrm{mmi}$ over a 6-mmi.

Table 3. HIE studies with marketed drug molecule substrates.

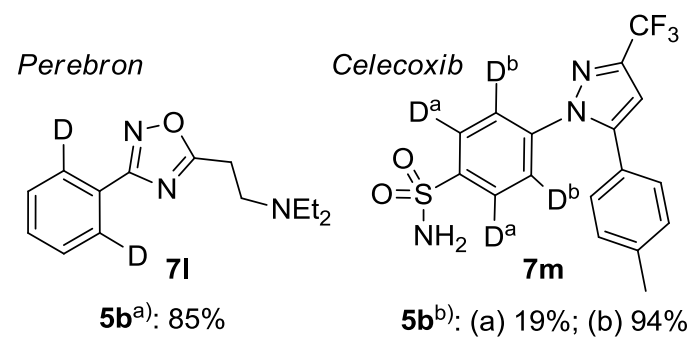

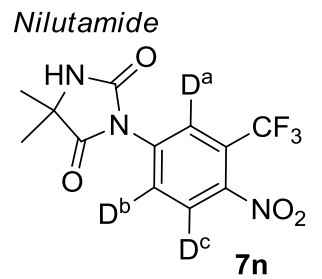

5cc): (a) $6 \%$; (b) $12 \%$; (c) $98 \%$

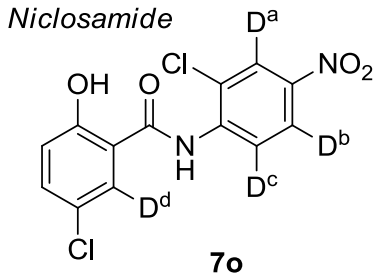

5ad): (a) $65 \%$; (b) 55\%;

(c) $52 \%$; (d) $62 \%$ a) $5 \mathrm{~mol} \%$ of Ir catalyst employed over 16 h. ${ }^{\text {b) }} 10 \mathrm{~mol} \%$ of Ir catalyst employed over $1 \mathrm{~h}$. ${ }^{\text {c) }} 2.5 \mathrm{~mol} \%$ of Ir catalyst employed over $1 \mathrm{~h}$. ${ }^{\text {d) }} 5 \mathrm{~mol} \%$ of Ir catalyst employed over $1 \mathrm{~h}$.

Following the exploration of substrate scope, we sought to gain further insight regarding the effectiveness of our novel system via the analysis of catalyst turnover. As shown in Table 4, the deuteration of acetophenone using catalyst $\mathbf{5 b}$ delivered very good turnover within a $6 \mathrm{~h}$ reaction period, using extremely low levels of catalyst. Under the same conditions, Crabtree's catalyst showed a vastly reduced efficiency; presumably due to its lower relative activity and instability over time. ${ }^{[12]}$

\section{Mechanistic Investigations}

Although the mechanism of iridium-catalysed HIE was proposed by Heys in $1996,{ }^{[5 \mathrm{~d}]}$ there exists only
Table 4. Catalyst turnover.

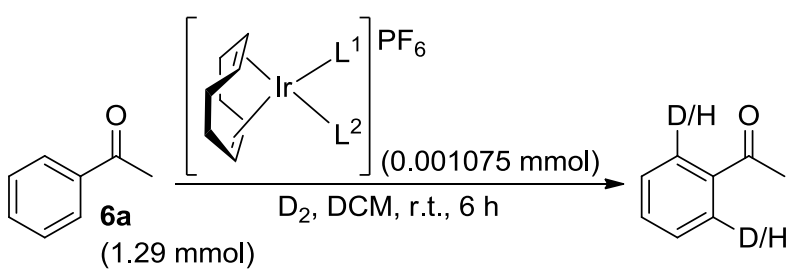

\begin{tabular}{lllll}
\hline Entry & $\begin{array}{l}\mathrm{L}^{1} / \mathrm{L}^{2} \\
\text { (catalyst) }\end{array}$ & \% D & TON $^{\mathrm{a})}$ & $\mathrm{TOF}^{\mathrm{b})}$ \\
\hline 1 & $\begin{array}{l}\text { IMes/PBn } \\
(\mathbf{5 b})\end{array}$ & 88 & 1056 & 176 \\
2 & $\begin{array}{l}\mathrm{Py} / \mathrm{Ph}_{3} \mathrm{P} \\
(\text { Crabtree's })\end{array}$ & 29 & 348 & 58 \\
\hline
\end{tabular}

a) Measured as no. moles of substrate converted/no. moles of catalyst employed. ${ }^{\text {b) }}$ Measured as no. moles of substrate converted/no. moles of catalyst employed/hours.

limited evidence to support the perceived sequence of events. ${ }^{[50]}$ Therefore, we were interested in embarking upon focused mechanistic investigations to increase the general comprehension of such catalysed hydrogen isotope exchange process. Further, by embedding our emerging iridium complex class within this study, we envisaged that any enhanced understanding could provide beneficial foundations to be used in the design of future catalyst systems.

Initially and to this end, an exchange reaction was carried out in an NMR tube, using deuterated dichloromethane, to allow us to monitor two key features in the proposed pathway: the initial removal of the cyclooctadiene (COD) unit from the iridium complex, and the resultant geometry of the major ligands around the metal centre. Since the formation of iridium hydrides is thought to be central to the removal of the COD ligand, the reverse exchange reaction (Scheme 5) was carried out by employing fully deuterated acetophenone 9 and exchanging with hydrogen gas, in an attempt to observe any potential Ir-hydride species. Complex $\mathbf{5 a}$ was chosen as this is the slowest acting of this series of catalysts, with 10 mol\% being employed in order to fully observe intermediate complexes and reaction progression by NMR analysis (see Supporting Information for full details).

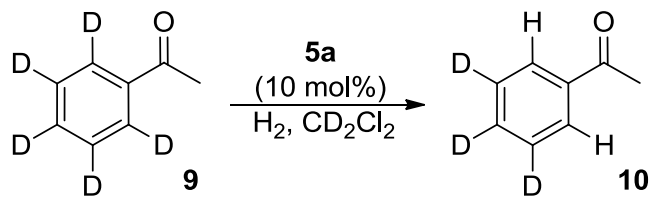

Scheme 5. Reverse exchange reaction monitored in an NMR tube.

Prior to the monitoring of the reaction, it was necessary to gather data on the parent complex, to allow the detection of any changes that occur as the overall process progresses. Accordingly, ${ }^{1} \mathrm{H}$ and ${ }^{31} \mathrm{P}$ 
NMR spectra of complex 5a were obtained in $\mathrm{CD}_{2} \mathrm{Cl}_{2}$. The most relevant ${ }^{1} \mathrm{H}$ spectrum peaks at the beginning of the reaction were the multiplets at 4.39-4.36 and $3.35-3.33 \mathrm{ppm}$, as shown in Figure 1. These peaks correspond to the olefinic protons of the COD ligand, and are expected to lose intensity and disappear at the beginning of the reaction as the COD is reduced. With regards to the ${ }^{31} \mathrm{P}$ NMR, the peak present at $16.35 \mathrm{ppm}$ corresponds to the phosphine ligand bound to the metal centre.
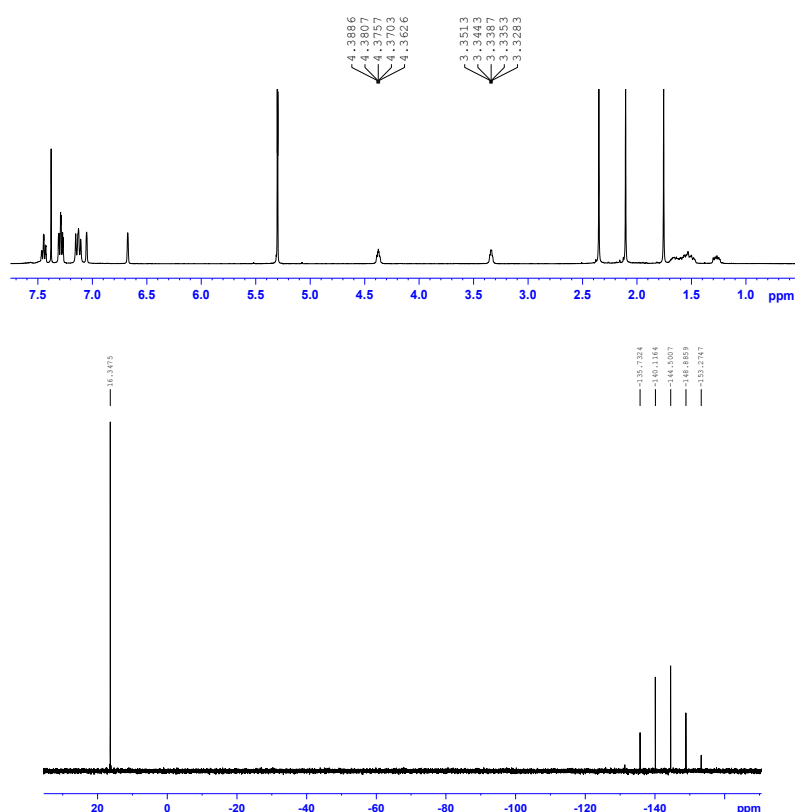

Figure 1. ${ }^{1} \mathrm{H}$ (top) and ${ }^{31} \mathrm{P}$ (bottom) NMR spectra of complex $\mathbf{5 a}$ in $\mathrm{CD}_{2} \mathrm{Cl}_{2}$.

Figure 2 shows a $2 \mathrm{D}{ }^{31} \mathrm{P} /{ }^{13} \mathrm{C}$ HMQC experiment of the same parent complex 5a. This allowed the ${ }^{2} J_{\mathrm{PC}}$ coupling constant between the bound phosphorus atom and the carbon of the carbene ligand to be established. It was envisaged that by carrying out this correlation experiment as the reaction proceeds, the observed magnitude of this ${ }^{2} J_{\mathrm{PC}}$ coupling constant would provide some indication of the geometry of the two major ligands. As presented in Figure 2, a distinct correlation was observed between the bound phosphine at $16.35 \mathrm{ppm}$ and the carbene carbon at $177 \mathrm{ppm}$. The ${ }^{2} J_{\mathrm{PC}}$ coupling constant was measured at $8.6 \mathrm{~Hz}$, in accord with these two ligands adopting a cis-arrangement in the parent complex. In turn, we were confident that the geometry of the ligands in any reaction intermediates could then be deduced by comparing the coupling constants obtained throughout the reaction. Consequently, the reaction (Scheme 5) was performed in an NMR tube using $\mathrm{d}_{5^{-}}$ acetophenone 9 and hydrogen gas, with $\mathrm{CD}_{2} \mathrm{Cl}_{2}$ as the reaction solvent. Following the initial addition of hydrogen gas, several peaks emerged in the ${ }^{1} \mathrm{H}$ NMR spectrum in the region of $-13-0 \mathrm{ppm}$, indicating the presence of the expected iridium hydrides. The reaction was then further monitored to assess the reduction and removal of the COD ligand, as shown by the disappearance of the multiplet peaks at 4.394.36 and 3.35-3.33 ppm; importantly, following this further analysis the peaks corresponding to the iridium hydrides had also disappeared, suggesting that these hydrides play a key role in the removal of the COD ligand. Furthermore, in the absence of the COD ligand, ${ }^{31} \mathrm{P}$ NMR analysis showed that the original phosphine signal $(16.35 \mathrm{ppm})$ had been replaced with a new peak at $20.80 \mathrm{ppm}$, indicating that the parent complex had been fully converted to an alternative phosphorus-containing iridium species within the reaction manifold.

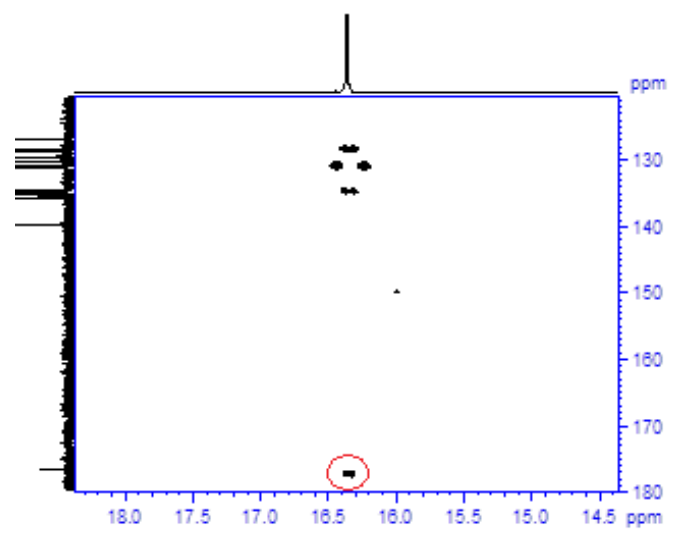

Figure 2. $2 \mathrm{D}{ }^{31} \mathrm{P} /{ }^{13} \mathrm{C}$ HMQC experiment of the parent complex.

To further investigate the new COD-free iridium intermediate, a second $2 \mathrm{D}$ HMQC ${ }^{13} \mathrm{C} /{ }^{31} \mathrm{P}$ correlation spectrum was obtained. As illustrated in Figure 3, the carbene carbon signal at $177 \mathrm{ppm}$ had been replaced by a new signal at $\sim 160 \mathrm{ppm}$. This change in chemical shift was accompanied by a correlation to the phosphine signal at $20.80 \mathrm{ppm}$, and with an appreciably elevated ${ }^{2} J_{\mathrm{PC}}$ coupling constant of $118 \mathrm{~Hz}$. Indeed, such large ${ }^{2} J_{\mathrm{PC}}$ coupling constants in similar iridium complexes, bearing phosphine and NHC ligands, have some literature precedent. For example, iridium(I) complex 11, depicted in Figure 4, has been shown to have the triphenylphosphine and bis-benzyl NHC ligands in a relative trans-arrangement. ${ }^{[19 a]}$ The data for this compound reveal the carbene carbon of the NHC to have a chemical shift of $177.6 \mathrm{ppm}$ and a ${ }^{2} J_{\mathrm{PC}}$ coupling constant of $116 \mathrm{~Hz}$. In an analogous manner, iridium(III) complex $\mathbf{1 2}$ has the tri-isopropylphosphine and IMes ligands in a transconfiguration, with a similar ${ }^{2} J_{\mathrm{PC}}$ coupling constant value of $108 \mathrm{~Hz} \cdot{ }^{[19 \mathrm{~b}]}$ However, the chemical shift of the carbene carbon in this latter complex is significantly more upfield than that of complex 11, with a value of $165 \mathrm{ppm}$. From the evidence obtained regarding the activated catalytic species in our HIE reaction, and from comparison with available literature data, ${ }^{[19]}$ it is proposed that the intermediate within this manifold has the phosphine and NHC ligands in a trans geometry; further, the ${ }^{13} \mathrm{C} N M R$ chemical shift of the carbene carbon is consistent 
with this new catalytic intermediate possessing an iridium(III) oxidation state.

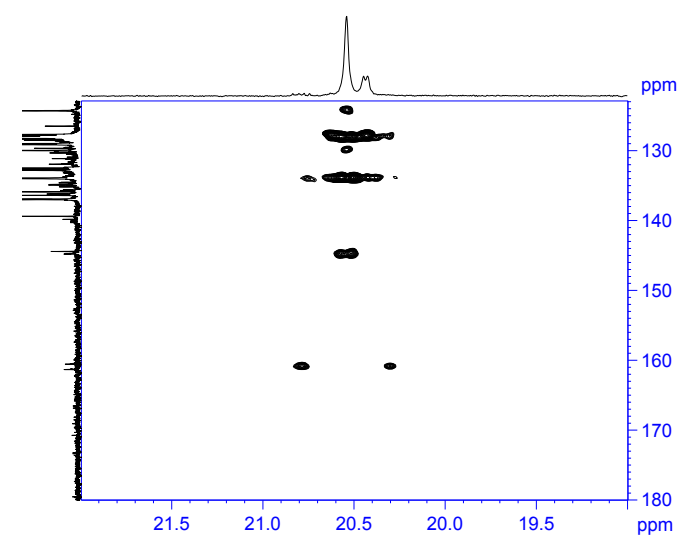

Figure 3. $2 \mathrm{D}{ }^{31} \mathrm{P} /{ }^{13} \mathrm{C}$ HMQC spectrum of intermediate $\mathrm{Ir}$ complex.<smiles>O=C(Cl)[I-](Cl)(Pc1ccccc1)C1N(Cc2ccccc2)C=CN1Cc1ccccc1</smiles>

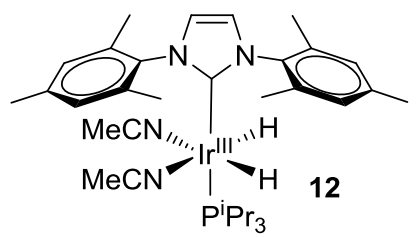

Figure 4. Known Ir complexes with phosphine/NHC ligands in a trans-arrangement.

To further support the above experimental evidence that the phosphine and NHC ligands align themselves in a trans-configuration, density functional theory (DFT) studies (see Supporting Information for full details on the level of theory used) were employed to calculate the relative energies of the proposed cis-and trans-isomers of the intermediate iridium species. Using Heys' mechanism as a guide, ${ }^{[5]}$ the most sterically hindered species along the catalytic cycle is envisaged to be that formed subsequent to oxidative insertion with the substrate, e.g. 13 with acetophenone (Figure 5). Therefore, the energetic ordering of the possible isomers of $\mathbf{1 3}$ was investigated to determine the probable active configuration within the HIE manifold.

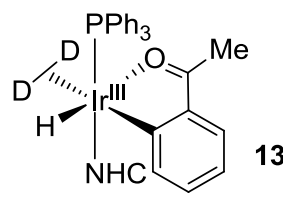

Figure 5. Oxidative addition intermediate in the catalytic cycle.

Potential orientations of the $\mathrm{D}_{2}$, hydride, and substrate ligands were investigated; however, all alternative configurations converged to one of the three isomers shown in Figure 6. In addition to the trans-isomer 13, two cis-isomers were also optimised to local minima on the potential energy surface (14 and 15, Figure 6). The relative energies of the three isomers indicate that $\mathbf{1 4}$ and $\mathbf{1 5}$ are destabilised by 8.83 and $10.12 \mathrm{kcal} / \mathrm{mol}$, respectively, relative to $\mathbf{1 3}$. These findings support the experimental evidence that the phosphine and NHC adopt a trans-orientation within the activated Ir species.

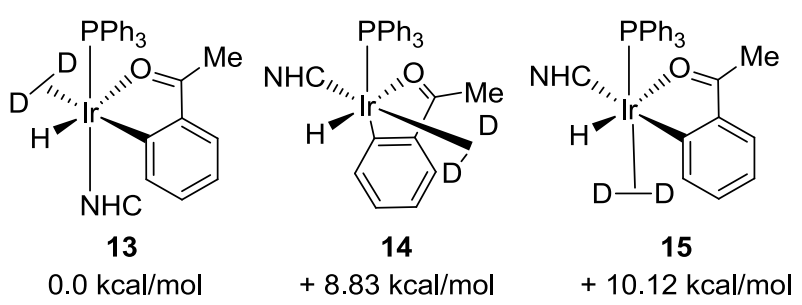

Figure 6. Optimised structures of $\mathbf{1 3}$ and its isomers at DFT level.

Our DFT calculations were further expanded to focus on the possible reaction pathway by which hydrogen isotope exchange proceeds. These more detailed investigations allowed the construction of the potential energy surface (PES) associated with the proposed catalytic cycle. Using that suggested by Heys as a basis, ${ }^{[5 \mathrm{~d}]}$ a mechanistic pathway employing our $\operatorname{Ir}(\mathrm{I})$ complexes in conjunction with acetophenone, 6a, was determined (Scheme 6). It is proposed that, following exposure to deuterium gas, complex 5a loses the COD ligand as $\mathrm{d}_{4}$-cyclooctane. The resulting coordinately unsaturated Ir species is stabilised by coordination of the substrate, e.g. 6a, delivering 16. Following oxidative addition to give $\mathbf{1 3}$, fluxionality of the dihydrogen hydride $(\mathbf{1 3} \rightarrow \mathbf{1 7})$ allows isotopic hydrogen to orient in the position cis to the Ir-C bond, resulting, ultimately, in reductive elimination $(\mathbf{1 7} \rightarrow \mathbf{1 8})$ and isotope incorporation into the ortho-position of the substrate aryl ring, 7a'. In relation to modifications to Heys' original mechanistic scheme, we now believe that the initial activated iridium species is stabilised by association of the substrate forming complex $\mathbf{1 6}$ in which the ortho aryl $\mathrm{C}-\mathrm{H}$ is agostically coordinated to the iridium centre. Furthermore and in a more general sense, a series of ${ }^{31} \mathrm{P}$ NMR magnetization transfer experiments, analogous to the work of Grubbs' within the field of ruthenium-catalysed olefin metathesis,${ }^{[20]}$ indicate that the phosphine ligand does not dissociate from the iridium metal centre throughout the catalytic cycle (see Supporting Information for experimental details).

All of the intermediates and transition states involved in our proposed catalytic cycle, with the incorporation of deuterium, have been fully optimised. Therefore, the enthalpy changes during the reaction progress have been monitored. Relative enthalpies of the stationary points on the PES and the barriers to oxidative addition, $\mathrm{H} / \mathrm{D}$ exchange, and reductive 


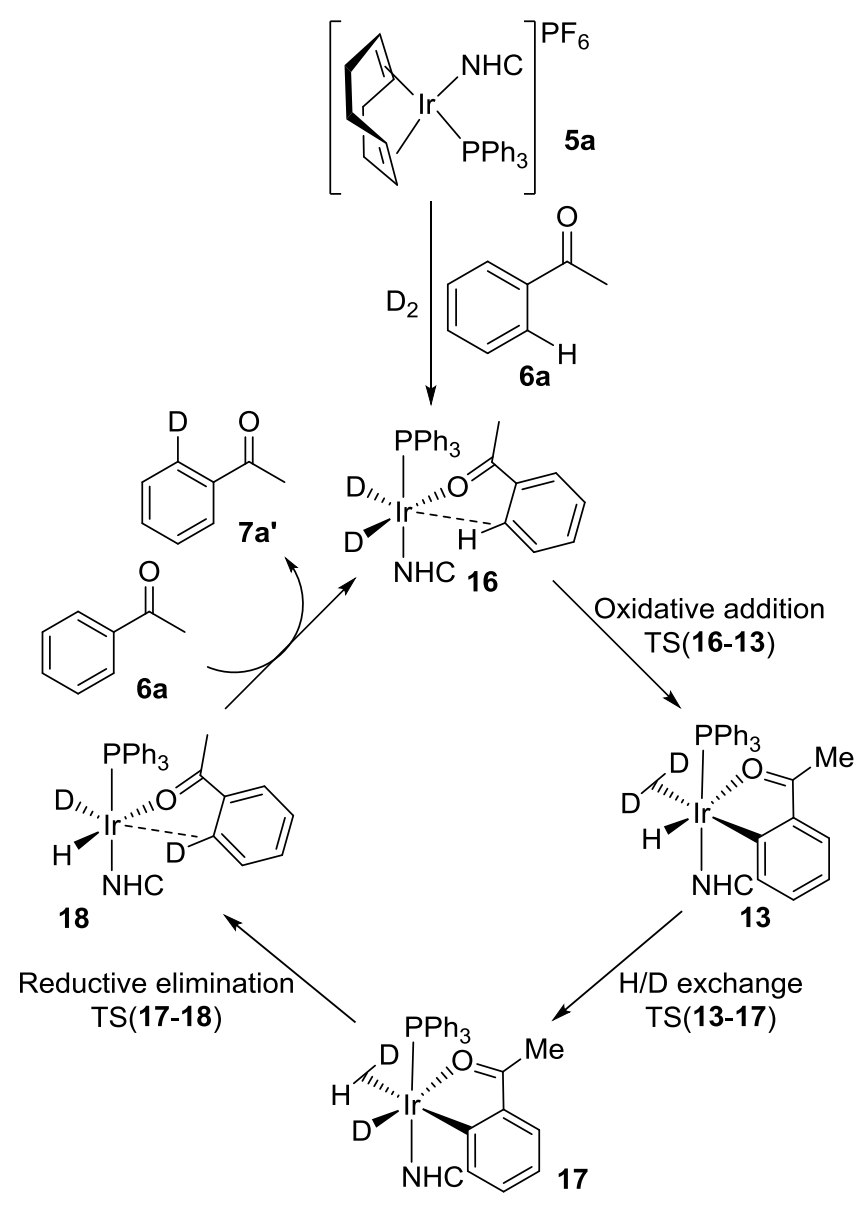

Scheme 6. Proposed HIE catalytic cycle.

elimination have also been calculated for each species shown in Scheme 6. In addition to the use of $\mathrm{PPh}_{3}$ and in order to probe the possibility of performing computational studies of more minimised cost, $\mathrm{PMe}_{3}$ was also investigated as the axial phosphine ligand (Table 5). The decreased ligand size in the $\mathrm{PMe}_{3}$ systems does not alter the mechanism of the reaction, nor does it strongly affect the geometry of the ligands around the equatorial plane, i.e. there is no large rearrangement of the ligands and the changes in bond lengths between the full $\left(\mathrm{PPh}_{3}\right)$ systems and the trimmed $\left(\mathrm{PMe}_{3}\right)$ version are calculated to be in the region of $0.02 \AA$ (see Supporting Information for details). Comparing the calculated energetic parameters detected along the reaction path for both $\mathrm{PPh}_{3}$ and $\mathrm{PMe}_{3}$ (Table 5), the axial phosphine substituent has a detectable impact on the energy of the oxidative addition step, with a difference of 1.43 $\mathrm{kcal} / \mathrm{mol}$ calculated for $\mathrm{TS}(\mathbf{1 6 - 1 3})$ between the species bearing $\mathrm{PPh}_{3}$ and the smaller $\mathrm{PMe}_{3}$.

With regards to the key steps in our proposed catalytic cycle and considering the $\mathrm{PPh}_{3}$ system, the oxidative addition of the iridium into the aryl $\mathrm{C}-\mathrm{H}$ bond, requires a moderate activation enthalpy of $16.70 \mathrm{kcal} / \mathrm{mol}$ (Table 5, Figure 7). Further, the conversion of $\mathbf{1 6}$ to $\mathbf{1 3}$ is endothermic by 3.66 $\mathrm{kcal} / \mathrm{mol}$ with respect to 16. The subsequent $\mathrm{H} / \mathrm{D}$ exchange step $(\mathbf{1 3} \rightarrow \mathbf{1 7})$ is calculated to be rapid, with an activation barrier of $2.25 \mathrm{kcal} / \mathrm{mol}$. In contrast to oxidative insertion, reductive elimination is favoured enthalpically, presumably due to the decrease in steric strain within the vicinity of the metal centre. Accordingly and based on this calculated PES, we can conclude that the ratelimiting step within such $\mathrm{H} / \mathrm{D}$ exchange processes appears to involve the oxidative addition or reductive elimination of the ortho- $\mathrm{C}-\mathrm{H}$ bonds. In a complementary experimental study, we strengthened this argument by observing a primary kinetic isotope effect of approximately 3.7 (see Supporting Information for full details). This suggests that $\mathrm{C}-\mathrm{H}$ activation $^{[21]}$ is, indeed, rate-limiting.

Having established the relative reaction energetics in HIE reactions employing acetophenone, $\mathbf{6 a}$, attention turned to the reactivity of our catalysts with respect to different target molecules. Such studies also offered the potential to explain the selective labelling of substrates via a $5-\mathrm{mmi}$ as opposed to a 6-mmi. Three substrates were selected for investigation: acetophenone, 6a, 2-phenylpyridine, 6e, and acetanilide, $\mathbf{6 h}$ (Figure 8).

In view of the similar energy values calculated for complexes bearing either $\mathrm{PPh}_{3}$ or $\mathrm{PMe}_{3}$ as the axial ligand, the remaining theoretical studies were performed with the smaller tertiary phosphine ligand in place. As our previous explorations had supported $\mathrm{C}-\mathrm{H}$ activation as being rate determining, the effects of the alternative substrates were examined within this portion of the catalytic process (Table 6). As

Table 5. Relative energies $(\Delta \mathrm{E})$, enthalpies $(\Delta \mathrm{H})$, and Gibbs free energies $(\Delta \mathrm{G})$ for the catalytic cycle calculated at DFT level (all are in $\mathrm{kcal} / \mathrm{mol})$.

\begin{tabular}{lllllll}
\hline \multirow{2}{*}{ Species } & $\Delta \mathrm{E}^{\mathrm{a})}$ & \multicolumn{3}{c}{$\Delta \mathrm{H}^{\mathrm{b})}$} & \multicolumn{1}{c}{$\Delta \mathrm{G}^{\mathrm{b})}$} & $\mathrm{PMe}_{3}$ \\
\cline { 2 - 7 } & $\mathrm{PPh}_{3}$ & $\mathrm{PMe}_{3}$ & $\mathrm{PPh}_{3}$ & $\mathrm{PMe}_{3}$ & $\mathrm{PPh}_{3}$ & 0.00 \\
\hline $\mathbf{1 6}$ & 0.00 & 0.00 & 0.00 & 0.00 & 0.00 & 18.35 \\
$\mathrm{TS}(\mathbf{1 6 - 1 3})$ & 17.21 & 18.14 & 16.70 & 18.13 & 18.65 & 0.27 \\
$\mathbf{1 3}$ & 3.33 & 0.93 & 3.66 & 1.20 & 2.88 & 2.10 \\
TS(13-17) & 5.86 & 3.17 & 5.91 & 3.66 & 5.05 & 0.30 \\
$\mathbf{1 7}$ & 3.43 & 0.93 & 3.75 & 1.19 & 3.00 & 18.62 \\
TS(17-18) & 17.39 & 18.39 & 16.94 & 18.35 & 18.50 & -0.42 \\
$\mathbf{1 8}$ & -0.42 & -0.44 & -0.45 & -0.48 & -0.41 & \\
\hline
\end{tabular}

\footnotetext{
${ }^{\text {a) }}$ Energies are zero-point corrected. ${ }^{\text {b) }}$ All enthalpies and Gibbs free energies are at $298.15 \mathrm{~K}$.
} 


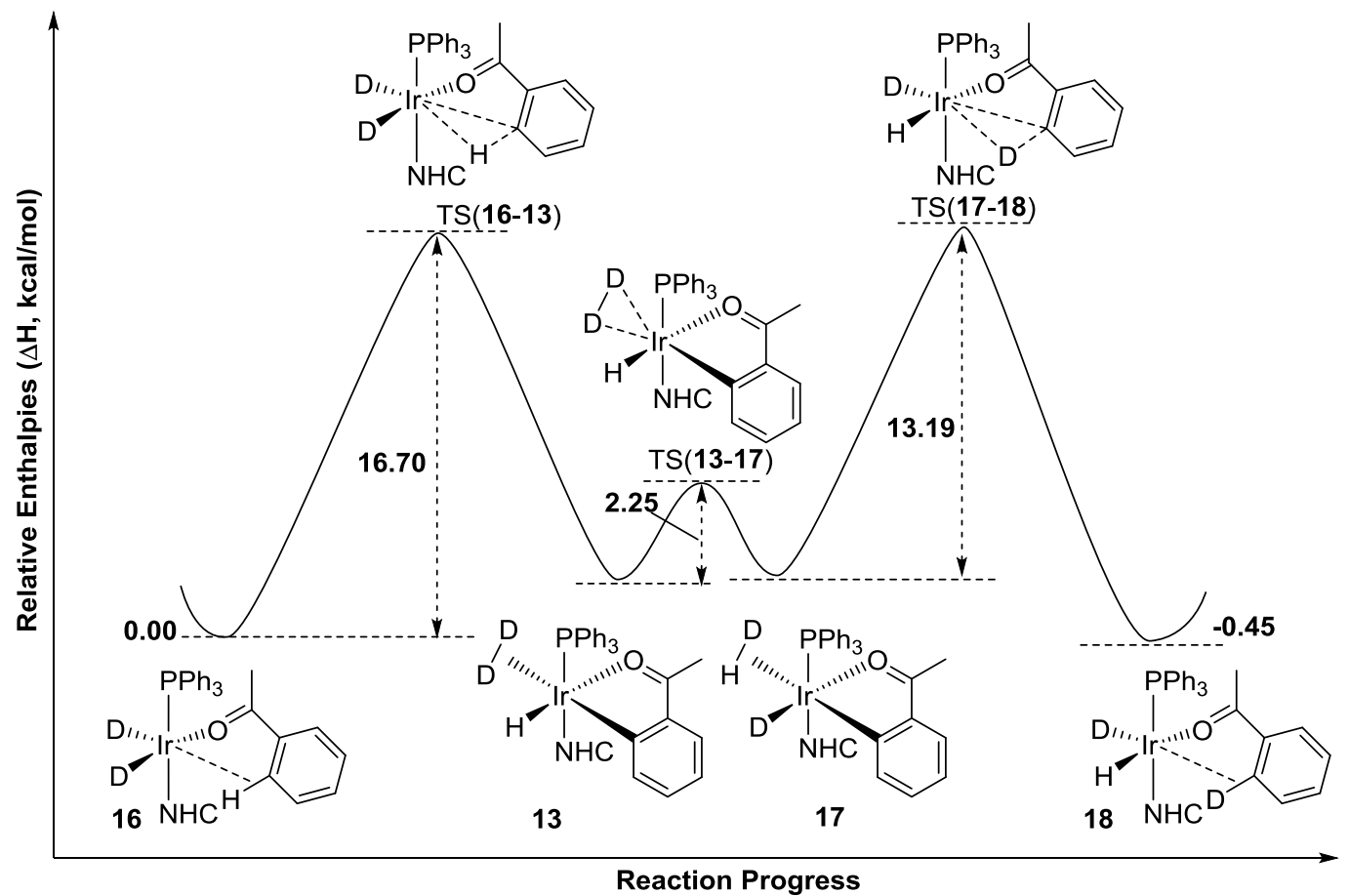

Figure 7. The reaction PES employing $\mathrm{Ph}_{3} \mathrm{P}$ as the phosphine ligand.<smiles>CC(=O)c1ccccc1</smiles>

$6 a$<smiles>c1ccc(-c2ccccn2)cc1</smiles>

$6 e$<smiles>CC(=O)Nc1ccccc1</smiles>

$6 \mathrm{~h}$

Figure 8. Substrates used in the DFT calculations.

revealed by the activation enthalpy values the substrates labelling via a 5-mmi, acetophenone, 6a, and 2-phenylpyridine, $\mathbf{6 e}$, were found to be most active. The identification of acetanilide, $\mathbf{6 h}$, as the least active substrate further supports our more general observations that compounds which are labelled via a 6-mmi are less reactive in our catalysed HIE reactions (vide supra). ${ }^{[5 \mathrm{~d}]}$

Table 6. Enthalpy changes for the oxidative addition step with three different substrates.

\begin{tabular}{llll}
\hline & \multicolumn{3}{c}{$\Delta \mathrm{H}^{\mathrm{a}), \mathrm{b})}$} \\
\cline { 2 - 4 } Species & $\mathbf{6 a}$ & $\mathbf{6 e}$ & $\mathbf{6 h}$ \\
\hline $\mathbf{1 6}$ & 0.00 & 0.00 & 0.00 \\
$\mathrm{TS}(\mathbf{1 6 - 1 3})$ & 18.13 & 17.53 & 23.04 \\
$\mathbf{1 3}$ & 1.20 & 2.73 & 5.11 \\
\hline a) & & &
\end{tabular}

a) All enthalpy changes are in $\mathrm{kcal} / \mathrm{mol}$ at $298.15 \mathrm{~K}$. ${ }^{\text {b) }}$ Calculations are based on the catalyst bearing the smaller $\mathrm{PMe}_{3}$ ligand.

Further theoretical calculations were performed to determine the binding energies of the three substrates under investigation (Table 7), since these had previously also been shown to influence labelling efficiencies. $^{[22]}$ The stabilisation energy, $\Delta H_{\text {bind }}$, resulting from the complexation of the substrate to the iridium metal, forming the species akin to 16, is calculated as the difference in enthalpy between the enthalpy of the optimised complex, 16, and the sum of the enthalpies of the optimised substrate and the optimised $\left[\left(\mathrm{D}_{2}\right) \operatorname{Ir}\left(\mathrm{PMe}_{3}\right)(\mathrm{NHC})\right]^{+}$complex. As illustrated by the values in Table 7 , all complexes have a stabilising interaction enthalpy with the substrates. It should be noted that the values presented represent binding enthalpies, as opposed to free energies, and, as such, entropic effects have not been accounted for. In all cases, the entropic contribution will negatively affect the stability of the complex relative to the separated reactants.

As shown in Table 7, substrate 6e binds most strongly to the iridium centre compared to other substrates, presumably due to the better binding ability of the more basic $\mathrm{N}$ atom, relative to a carbonyl $\mathrm{O}$ atom. In addition, substrate $\mathbf{6 h}$ binds to the iridium centre with a similar strength as displayed by substrate $\mathbf{6 a}$. In both cases the coordination proceeds via interaction of the oxygen atom lone pair of electrons to the metal core. Hence, it can be deduced that the activation enthalpy, rather than the binding enthalpy, dictates the more effective labelling via a 5-over a 6-mmi.

Table 7. Calculated binding energies $\left(\mathrm{PR}_{3}=\mathrm{PMe}_{3}\right)$.

\begin{tabular}{llll}
\hline Substrate & $\mathbf{6 a}$ & $\mathbf{6 e}$ & $\mathbf{6 h}$ \\
$\Delta \mathrm{H}_{\text {bind }}$ & -23.48 & -31.42 & -23.94 \\
\hline a) &
\end{tabular}

a) All relative enthalpies are in $\mathrm{kcal} / \mathrm{mol}$ at $298.15 \mathrm{~K}$. 


\section{Incorporation of Tritium}

Following the success of our emerging iridium phosphine/carbene species for H/D exchange, and with an improved understanding of the catalytic mechanism, investigations were undertaken to ascertain whether these Ir species could also facilitate hydrogen-tritium exchange reactions. Since radionuclides can be detected more sensitively than stable isotopes, it is common practice within pharmaceutical laboratories to prepare both the stable isotopically-labelled molecule and the radio-labelled compound. ${ }^{[2 \mathrm{c}, 9]}$ Therefore, it was important to determine the activity of the developed catalysts in the labelling of substrates with tritium. Due to the more challenging hydrogen-tritium exchange process, based on the increased tritium-tritium bond strength, $5 \mathrm{~mol} \%$ catalyst loading was required. Nonetheless, over a relatively short reaction time of only 2 hours, a successful tritiation protocol was achieved (Table 8).

Table 8. Tritiation studies with catalysts 5a-c. ${ }^{\text {a),b) }}$
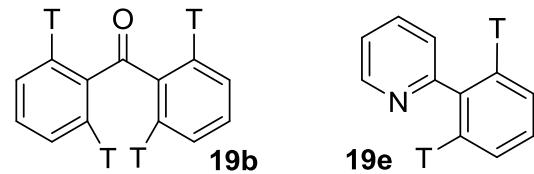

5b: $\mathrm{T}_{\mathrm{o}}(3), \mathrm{T}_{1}(23), \mathrm{T}_{2}$ (41), $T_{3}(27), T_{4}(7)$

5a: $T_{0}(15), T_{1}(20)$,

$T_{2}(64), T_{3}(1)$
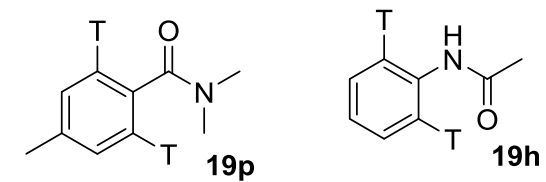

5b: $T_{0}(64), T_{1}(31)$, $\mathrm{T}_{2}$ (5)

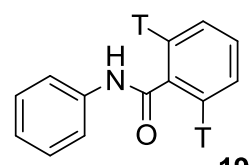

19j

5b: $T_{\circ}(93), T_{1}(7)$

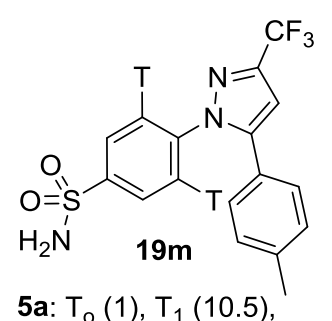

5c: $T_{0}(15), T_{1}(46)$ $\mathrm{T}_{2}(38), \mathrm{T}_{3}(1)$ a) $5 \mathrm{~mol} \%$ of Ir catalyst employed over 2 hours. ${ }^{\text {b) }} \mathrm{T}_{\mathrm{x}}$ (where $\mathrm{x}=0,1,2,3,4$ ) refers to the number of tritium atoms incorporated into the molecule, e.g. for $\mathbf{1 9 b}, \mathrm{T}_{1}(23)$ indicates that $23 \%$ of the sample contained one tritium atom. See Supporting Information for further details.

Tritiation via a 5 -mmi proved relatively facile with high levels of $T$ uptake being observed $(19 b, 19 e$, 19p). Perhaps as anticipated, hydrogen-tritium exchange through a 6-mmi was less efficient, with only $7 \%$ incorporation achieved with acetanilide, $\mathbf{1 9 h}$. As anticipated, only the position activated through the $5-\mathrm{mmi}$ in $\mathbf{1 9} \mathbf{j}$ was labelled regioselectively and with good levels of effectiveness. Of particular note was the extremely successful tritiation of the drug molecule Celecoxib, 19m; further and in contrast with the analogous deuterium experiment, only the positions ortho to the pyrazole directing group displayed tritium incorporation. With respect to all examples shown in Table 8, we were pleased to note that the process was remarkably clean, with no significant tritiated by-products being observed. Indeed, in previous studies we have revealed an appreciably different reaction profile, possessing an array of T-possessing by-products, when Crabtree's catalyst is employed. ${ }^{\text {[] }}$

\section{Conclusions}

By embedding a bulky $N$-heterocyclic carbene ligand in combination with different phosphine ligands, a series of highly active iridium-based catalysts have been developed for hydrogen isotope exchange. Such catalysts have been shown to produce high incorporations of deuterium and tritium adjacent to a good range of relevant functional units within a series of compounds, including pharmaceutically-active agents. Additionally, combined experimental and computational studies have led to a deeper understanding of the nature of such catalyst systems and the active species generated, as well the overall reaction mechanism. These investigations have indicated that the $\mathrm{C}-\mathrm{H}$ activation process is the ratelimiting step within this HIE manifold. Further, the $\mathrm{C}-\mathrm{H}$ activation event also constitutes the regiochemistry-determining step when both 5- and 6metallocyclic intermediates are possible, leading to appreciable selectivities within the established exchange processes.

With regards the pivotal $\mathrm{C}-\mathrm{H}$ activation, we believe that the electron-rich ligand set employed as part of the emerging catalyst systems is central to the facilitation of the requisite oxidative addition step within the catalytic cycle. Further, the sterically crowded ligand sphere will, in turn, aid reductive elimination. In relation to this latter point, when sterically less demanding phosphine/NHC combinations were applied within our laboratory, the resulting complexes displayed appreciably lowered activity within HIE processes. It should also be noted that the bulky NHC and phosphine ligands used within our series of iridium complexes could provide the active catalytic species, formed within the reaction manifold, with enhanced levels of stability by preventing the existence of inactive iridium clusters $^{[12]}$ or driving the presence of monomeric active iridium species..$^{[1 \mathrm{~b}]}$

Overall, the novel catalysts developed for HIE reactions within this programme have the clear potential to replace Crabtree's catalyst as the industry standard in this area. Moreover, these complexes are stable in air and at room temperature, retaining their activity over prolonged storage periods. The 
experimental and computational methods employed here, aligned with the associated mechanistic and theoretical insights delivered through this study, are now being employed within our laboratory in endeavours to develop catalyst systems of further enhanced activity and more widespread substrate applicability.

\section{Computational Methods}

Density functional theory (DFT) was employed to calculate the electronic structures and energies for all species involved in H/D exchange reactions. A hybrid meta-GGA exchange correlation functional $\mathrm{M}^{[23]}$ was used in conjunction with the $6-31 \mathrm{G}(\mathrm{d}, \mathrm{p})^{[24]}$ basis set for main group non-metal atoms and the Stuttgart $\mathrm{RSC}^{[25]}$ effective core potential along with the associated basis set for Ir. Harmonic vibrational frequencies are calculated (with the incorporation of deuterium wherever needed) at the same level of theory to characterise respective minima (reactants, intermediates, and products with no imaginary frequency) and first order saddle points (TSs with one imaginary frequency). All calculations have been performed with the GAUSSIAN 09 quantum chemistry programme package. More detailed discussion of the computational methods, with full references, can be found in the Supporting Information.

\section{Experimental Section}

\section{General Procedure for the Synthesis of Complexes 5a-} 5e:

A flame dried and nitrogen cooled Schlenk tube was charged with $\mathbf{3}$ and dry benzene $(10 \mathrm{~mL})$. The solution was treated with freshly prepared 1 $M$ sodium ethoxide solution and stirred for 10 minutes. After this time, 4 was added and the mixture stirred for $5 \mathrm{~h}$ at r.t. The solvent was removed under high vacuum and the residue triturated with dry ether prior to filtration through celite under $\mathrm{N}_{2}$. After solvent exchange to dry THF (15 $\mathrm{mL}), \mathrm{AgPF}_{6}$ was added and the resultant slurry stirred for 30 minutes at r.t. After filtration through celite under $\mathrm{N}_{2}$, the solution was treated with phosphine and the resultant ruby red solution was stirred for $2 \mathrm{~h}$. Purification by recrystallisation yielded the desired complex.

\section{Standard Hydrogen Isotope Exchange Procedure:}

A flame dried and nitrogen cooled $250 \mathrm{~mL}$ 3-neck round bottomed flask, equipped with two stopcock valves and a suba seal, was charged with the iridium complex $(5 \mathrm{~mol} \%)$ and dry DCM $(2.5 \mathrm{~mL})$, followed by the substrate $(0.215$ mmol). The suba seal was replaced with a greased glass stopper and the reaction vessel was cooled to $-78{ }^{\circ} \mathrm{C}$ in a dry ice/acetone bath, prior to being purged twice with nitrogen. The flask was then evacuated and filled with deuterium gas via balloon. The flask was removed from the slurry and allowed to warm to room temperature. (NOTE: the glass stopper must be physically restrained as the reaction mixture warms to room temperature; further standard caution should also be observed ensuring the robust nature of the glassware used and the employment of less vigorous stirring at this stage in the process). The reaction mixture was then allowed to stir vigorously at room temperature for the allotted reaction time. After this time, excess deuterium gas was removed from the system under vacuum. The reaction mixture was concentrated under reduced pressure and the catalyst complex was precipitated using diethyl ether $(\sim 10 \mathrm{~mL})$ and removed by filtration through a plug of silica. Concentration of the filtrate under reduced pressure yielded the product/substrate mixture, which was analysed by ${ }^{1} \mathrm{H}$ NMR spectroscopy. The level of isotope incorporation into the substrate was determined by ${ }^{1} \mathrm{H}$ NMR analysis of the reaction products. As such, the residual proton signal from the site of incorporation was compared against that of a site where incorporation was not expected or occurred.

Full details of all experimental procedures, analyses, and DFT calculations (including optimised Cartesian coordinates) can be found in the Supporting Information.

\section{Acknowledgements}

We thank the University of Strathclyde (J.A.B.), AstraZeneca, $R \& D$ Mölndal (S.I. and A.R.C.), and the Carnegie Trust (M.R.) for postgraduate studentship funding. Mass spectrometry data were acquired at the EPSRC UK National Mass Spectrometry Facility at Swansea University. T.T. thanks the Glasgow Centre for Physical Organic Chemistry for funding.

\section{References}

[1] a) R. Mahajan, K. Gupta, J. Pharm. Bioallied Sci. 2010, 2, 307-313; b) J. Arrowsmith, P. Miller, Nature Reviews Drug Discovery 2013, 12, 569-569.

[2] a) W. J. S. Lockley, J. Label. Compd. Radiopharm. 2007, 50, 779-788; b) J. Atzrodt, V. Derdau, T. Fey, J. Zimmermann, Angew. Chem. Int. Ed. 2007, 46, 77447765 ; c) E. M. Isin, C. S. Elmore, G. N. Nilsson, R. A. Thompson, L. Weidolf, Chem. Res. Toxicol. 2012, 25, 532-542; d) W. J. S. Lockley, A. McEwen, R. Cooke, J. Label. Compd. Radiopharm. 2012, 55, 235-257.

[3] For examples using platinum catalysis, see: J. L. Garnett, R. J. Hodges, J. Am. Chem. Soc. 1967, 89, 4546-4547.

[4] For examples using rhodium catalysis, see: a) M. R. Blake, J. L. Garnett, I. K. Gregor, W. Hannan, K. Hoa, M. A. Long, J. Chem. Soc., Chem. Commun. 1975, 930-932; b) W. J. S. Lockley, Tetrahedron Lett. 1982, 23, 3819-3822; c) W. J. S. Lockley, J. Label. Compd. Radiopharm. 1984, 21, 45-57; d) W. J. S. Lockley, J. Label. Compd. Radiopharm. 1985, 22, 623-630; e) D. Hesk, J. R. Jones, W. J. S. Lockley, J. Pharm. Sci. 1991, 80, 887-890.

[5] For examples using iridium catalysis, see: a) R. H. Crabtree, E. M. Holt, M. Lavin, S. M. Morehouse, Inorg. Chem. 1985, 24, 1986-1992; b) R. Heys, J. Chem. Soc., Chem. Commun. 1992, 680-681; c) J. R. Heys, A. Y. L. Shu, S. G. Senderoff, N. M. Phillips, J. Label. Compd. Radiopharm. 1993, 33, 431-438; d) A. Y. L. Shu, W. Chen, J. R. Heys, J. Organomet. Chem. 1996, 524, 87-93; e) L. P. Kingston, W. J. S. Lockley, A. N. Mather, E. Spink, S. P. Thompson, D. J. Wilkinson, Tetrahedron Lett. 2000, 41, 2705-2708; f) J. G. Ellames, S. J. Gibson, J. M. Herbert, W. J. Kerr, A. H. McNeill, Tetrahedron Lett. 2001, 42, 6413-6416; g) 
P. W. C. Cross, J. G. Ellames, J. S. Gibson, J. M. Herbert, W. J. Kerr, A. H. McNeill, T. W. Mathers, Tetrahedron 2003, 59, 3349-3358; h) B. McAuley, M. J. Hickey, L. P. Kingston, J. R. Jones, W. J. S. Lockley, A. N. Mather, E. Spink, S. P. Thompson, D. J. Wilkinson, J. Label. Compd. Radiopharm. 2003, 46, 1191-1204; i) J. G. Ellames, J. S. Gibson, J. M. Herbert, W. J. Kerr, A. H. McNeill, J. Label. Compd. Radiopharm. 2004, 47, 1-10; j) M. B. Skaddan, C. M. Yung, R. G. Bergman, Org. Lett. 2004, 6, 11-13; k) C. M. Yung, M. B. Skaddan, R. G. Bergman, J. Am. Chem. Soc. 2004, 126, 13033-13043; 1) R. N. Garman, M. J. Hickey, L. P. Kingston, B. McAuley, J. R. Jones, W. J. S. Lockley, A. N. Mather, D. J. Wilkinson, J. Label. Compd. Radiopharm. 2005, 48, 75-84; m) J. M. Herbert, A. D. Kohler, A. H. McNeill, J. Label. Compd. Radiopharm. 2005, 48, 285-294; n) J. Krüger, B. Manmontri, G. Fels, Eur. J. Org. Chem. 2005, 14021408; o) J. R. Heys, J. Label. Compd. Radiopharm. 2007, 50, 770-778; p) J. R. Heys, C. S. Elmore, J. Label. Compd. Radiopharm. 2009, 52, 189-200; q) R. Salter, J. Label. Compd. Radiopharm. 2010, 53, 645657.

[6] For examples using nickel catalysis, see: J. R. Heys, J. Label. Compd. Radiopharm. 2010, 53, 716-721.

[7] a) R. H. Crabtree, H. Felkin, G. E. Morris, J. Organomet. Chem. 1977, 141, 205-215; b) R. H. Crabtree, Acc. Chem. Res. 1979, 12, 331-337.

[8] a) D. Hesk, P. R. Das, V. Evans, J. Label. Compd. Radiopharm. 1995, 36, 497-502; b) G. J. Ellames, J. S. Gibson, J. M. Herbert, A. H. McNeill, Tetrahedron 2001, 57, 9487-9497; c) S. C. Schou, J. Label. Compd. Radiopharm. 2009, 52, 376-381; d) D. Hesk, C. F. Lavey, P. McNamara, J. Label. Compd. Radiopharm. 2010, 53, 722-730; e) M. Vliegen, P. Haspeslagh, W. Verluyten, J. Label. Compd. Radiopharm. 2012, 55, 155-157.

[9] G. N. Nilsson, W. J. Kerr, J. Label. Compd. Radiopharm. 2010, 53, 662-667.

[10] H. M. Lee, T. Jiang, E. D. Stevens, S. P. Nolan, Organometallics 2001, 20, 1255-1258.

[11] a) L. D. Vásquez-Serrano, B. T. Owens, J. M. Buriak, Chem. Commun. 2002, 2518-2519; b) L. D. VázquezSerrano, B. T. Owens, J. M. Buriak, Inorg. Chim. Acta 2006, 359, 2786-2797.

[12] Crabtree's catalyst is known to be thermally unstable and is prone to deactivation via the irreversible formation of inactive clusters, see a) D. F. Chodosh, R. H. Crabtree, H. Felkin, G. E. Morris, J. Organomet. Chem. 1978, 161, C67-C70; b) ref. 7b).
[13] a) J. A. Brown, S. Irvine, A. R. Kennedy, W. J. Kerr, S. Andersson, G. N. Nilsson, Chem. Commun. 2008, 1115-1117; b) For a recent disclosure of the use of complexes such as [(COD) $\operatorname{Ir}(\mathrm{IMes}) \mathrm{Cl}]$, a precursor to catalysts 5a-e, in HIE processes, see A. R. Cochrane, S. Irvine, W. J. Kerr, M. Reid, S. Anderson, G. N. Nilsson, J. Label. Compd. Radiopharm. 2013, 56, 451-454; c) Catalysts 5a-c are now available commercially from Strem Chemicals Ltd.

[14] L. S. Bennie, C. J. Fraser, S. Irvine, W. J. Kerr, S. Andersson, G. N. Nilsson, Chem. Commun. 2011, 47, 11653-11655.

[15] C. D. Forsyth, W. J. Kerr, L. C. Paterson, Synlett 2013, 24, 587-590.

[16] C. Kocher, W. A. Herrmann, J. Organomet. Chem. 1997, 532, 261-265.

[17] D. Balcells, E. Clot, O. Eisenstein, Chem. Rev. 2010, 110, 749-823.

[18] During the construction of this manuscript a study appeared divulging labelling adjacent to a secondary sulfonamide unit albeit at more elevated temperatures $\left(90{ }^{\circ} \mathrm{C}\right)$ in a higher boiling solvent: M. Parmentier, T. Hartung, A. Pfaltz, D. Muri, Chem. Eur. J. 2014, DOI: $10.1002 /$ chem.201402078.

[19] a) Y.-H. Chang, C.-F. Fu, Y.-H. Liu, S.-M. Peng, J.-T. Chen, S.-T. Liu, Dalton Trans. 2009, 861-867; b) O. Torres, M. Martín, E. Sola, Organometallics 2009, 28, 863-870.

[20] M. S. Sanford, M. Ulman, R. H. Grubbs, J. Am. Chem. Soc. 2001, 123, 749-750.

[21] E. M. Simmons, J. F. Hartwig, Angew. Chem. Int. Ed. 2012, 51, 3066-3072.

[22] A. R. Cochrane, C. Idziak, W. J. Kerr, B. Mondal, L. C. Paterson, T. Tuttle, S. Andersson, G. N. Nilsson, Org. Biomol. Chem. 2014, 12, 3598-3603.

[23] Y. Zhao, D. G. Truhlar, Theor. Chem. Acc. 2008, 120, 215-241.

[24] a) W. J. Hehre, R. Ditchfield, J. A. Pople, J. Chem. Phys. 1972, 56, 2257-2261; b) M. M. Francl, W. J. Petro, W. J. Hehre, J. S. Binkley, M. S. Gordon, D. J. DeFrees, J. A. Pople, J. Chem. Phys. 1982, 77, 36543665 .

[25] D. Andrae, U. Häußermann, M. Dolg, H. Stoll, H. Preuß, Theor. Chim. Acta 1990, 77, 123-141. 


\section{FULL PAPER}

The Synthesis of Highly Active Iridium(I)

Complexes and their Application in Catalytic

Hydrogen Isotope Exchange

Adv. Synth. Catal. Year, Volume, Page - Page

Jack A. Brown, ${ }^{\mathrm{a}}$ Alison R. Cochrane,${ }^{\mathrm{a}}$ Stephanie

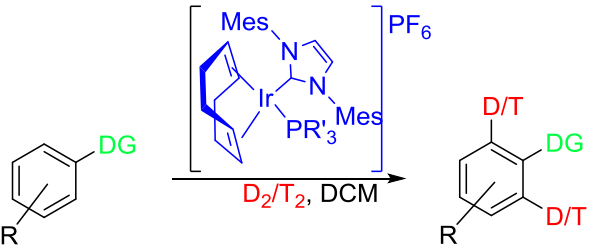

Irvine, ${ }^{a}$ William J. Kerr, ${ }^{\text {a* }}$ Bhaskar Mondal, ${ }^{\text {a John }}$

$D G=$ directing group

- High Catalyst Activity and Turnover

- Regioselective Labeling

- Theoretical Studies

A. Parkinson, ${ }^{a}$ Laura C. Paterson, ${ }^{a}$ Marc Reid,${ }^{\mathrm{a}}$ Tell

- Mechanistic Analysis

Tuttle, ${ }^{a}$ Shalini Andersson, ${ }^{b}$ and Göran N. Nilsson ${ }^{b}$ 